\title{
Is It Competent Enough for Handling Foodservice Quality? From the Students’ Viewpoint of Self-perceived Competence and the Contribution of Hospitality Course
}

\begin{abstract}
Wen-Hwa Ko
Fu-Jen University, New Taipei City, Taiwan

This study evaluated the self-perceived importance and competence with regard to foodservice quality of hospitality students in Taiwan. The study used a 6-dimension food quality scale to gather self-assessed data from student participants. A total of 400 questionnaires were sent out, with 355 (88.75\%) returned, validated, and used in research. In the dimension of perceived importance, participants placed the highest importance on "food safety" and the lowest importance on "food characteristics". In the dimension of competence, participants placed the highest competence on "service quality", while the competence concerning “culinary skill” was lower. An importance-performance analysis (IPA) identified "food safety" as showing the greatest be improved among the six dimensions. The courses and internship experience predicted $26.4 \%$ of the variability in perceived competence of foodservice quality. Both the two variables showed a statistical significance. The culinary courses had a greater impact on food quality-related perceptions than did either hospitality professional or general management courses. Finally, this study identified that the school courses had a positive contribution to the competence of foodservice quality and with hospitality students who completed school courses having better quality perception competence than those who had not.
\end{abstract}

Keywords: hospitality courses, foodservice quality, food safety, competence

\section{Introduction}

Food quality and service quality are critical factors in determining the success of restaurant operations, and the continuous improvement of foodservice quality will help to ensure the sustained commercial viability of businesses in the hospitality sector. In Taiwan, a rapidly expanding hospitality sector has encouraged universities and colleges to establish hospitality-related departments, and institutes of secondary and tertiary education continue to expand foodservice management, tourism and restaurant and hospitality marketing programs. Restaurant and hospitality education programs work to integrate the latest technologies, strategies, and methodologies into classroom learning to enhance the competitive strength of graduates in both the domestic and global hospitality industries. Food quality is the most important factor influencing restaurant success, followed by customization and the attitudes of foodservice staff (Parsa, Self, Njite, \& King, 2005). Consumers have been paying increasing attention to food quality and food safety in Taiwan. Quality assurance

Wen-Hwa Ko, associate professor, Department of Restaurant, Hotel, and Institutional Management, Fu-Jen University. Email: 073770@mail.fju.edu.tw. 
is of critical importance to maintaining and increasing consumer trust in the quality and safety of food (Jevsnik, Hlebec, \& Raspor, 2008). Christou (1999) found that hospitality education in Taiwan provides a critical foundation for managerial skills development in the hospitality sector. Although hospitality is a popular education track for students and a focus of promotion for both industry and government, many students in Taiwan lack a basic understanding of the requirements and the expectations of the hospitality curriculum prior to program admission. Furthermore, hospitality students experience a significant gap between their expectations and experiences in the hospitality industry after graduation (Horng, 2007). While hospitality industry executives frequently express that current hospitality education curricula taught at schools frequently fail to meet industry needs, and hospitality program graduates also frequently express frustration at being unable to apply what they have learned to their jobs. Some studies have identified a large gap between the education received by hospitality students and the expectations that the hospitality industry has of new employees (Christou, 1999; Horng, 2004). Hospitality education should provide students with the skills and knowledge needed by the hospitality industry. Besides professional courses in schools, before graduation, students of the hospitality department will experience a long period of internship to apply knowledge acquired to workplace and obtain techniques which are not instructed in schools. Through combination of courses and internship, students of the hospitality department will approach the industry. Scope of foodservice quality is broad. Besides food, it also includes environmental perception, consumer service, etc.. Besides courses in schools, students can learn the skills by internship or work in workplace. Students' self-perceived quality in foodservice helps enhance their professional competency and it leads to more specific improvement guidelines for firms. Therefore, if students have recognition and judgment of foodservice quality before entering workplace and reinforce their shortages, they will be allowed to join in severely competitive foodservice job market. The hospitality quality awareness of college students has been associated with their future professional confidence as hospitality industry employees. This study thus investigates the level of foodservice quality competence awareness and the importance for the courses among current hospitality students, and aims to understand the gap between perceived importance and perceived competence among participants, in order to suggest a curriculum framework best suited to provide students with the requisite technical proficiencies.

\section{Literature Review}

\section{Foodservice Quality}

Quality is a main determinant of consumer food choice (Olsen, Harmsen, \& Friis, 2008). Assessment of consumer satisfaction with the foodservice is an essential component of dietetic quality management processes. If the food and service do not suit consumers' tastes, consumption declines and the risk of malnutrition increases (Wright, Connelly, \& Capra, 2006). Thus, quality management is a core theme for corporate operational sustainability, and food quality is one of the critical components of the dining experience (Namkung \& Jang, 2007). Food and beverage (F\&B) quality requirements embrace both consumer-specific preferences such as nutrition, presentation, and taste, and general performance requirements such as uniform quality, on-time delivery, product differentiation, and R\&D-based improvements that are essential to continued innovation and improved reliability and consistency (Sanderson \& Uzumeri, 1995; Baldwin \& Clark, 1997). However, foodservice dimensions include historical and cultural factors, product development, service, design, product evaluation, physiology, nutrition, psychology, markets, health, environment and space, interpersonal relations, product characteristics, and comprehensive management systems (Meiselman, 2008). 
Peri (2004) argued that consumer demands for foodservice quality reflect either a food product aspect or market and promotional aspect across five major dimensions associated with 13 factors. These include: (1) product factors: safety requirements, conformity to product standards, nutritional needs, and sensory satisfaction demands; (2) psychological responsiveness factors: requirements related to the production process and ethics; (3) assignment of responsibility factors: product accreditation and traceability; (4) product/packaging system factors: demands for packaging functionality and aesthetically pleasing designs, product information provision, and convenience; and (5) product/systemic market demand factors: usability and price considerations. The above and a review of the relevant literature highlight that the concept of foodservice quality includes both products and consumer preferences. Thus, a broad definition of foodservice quality must address both food-related (including food characteristics, culinary arts, and hygiene/safety) and consumer preference-related concerns (including environment/ambiance, marketing/promotion, and service).

Food characteristics. The essence of hospitality quality is the food. The characteristics of food include aspects such as microorganisms and sensory experiences, such as aroma, taste, and appearance; among these, appearance and flavor are the major factors reflecting the hospitality quality (Seo \& Shanklin, 2006). Sulek and Hensley (2004) pointed out that the three key features determining food quality are food safety, food attractiveness, and food acceptance; the latter two include taste, appearance, texture, color, temperature, and portion. The freshness of food is also an important indicator of its acceptance (Johns, Tyas, Ingold, \& Hopkinson, 1996; Kivela, Inbakaran, \& Reece, 1999; Acebron \& Dopico, 2000); therefore, freshness is one of the prime methods to inspect food quality and includes brittleness, succulence, and fragrance (Peneau, Hoehn, Roth, Escher, \& Nuessli, 2006). Kivela, Inbakaran, and Reece (2000) proposed key factors concerning hospitality quality, including food freshness, menu types, and nutrition, to explain the effect of hospitality quality on customer satisfaction and repurchase intention.

Culinary arts. Culinary art combines cuisine and art, i.e., culinary art is the combination of cooking technique and artistic aesthetics. Lin (2007) suggested that culinary art is a discipline, covering food science, food preparation knowledge, cooking techniques, aesthetic art, and dietary culture; it is also a skill combining science and professional artistic knowledge. Yang (2003) divided the professional competency of chefs into six dimensions: food cooking-related knowledge, food preparation ability, safety and hygiene knowledge, hospitality business and management knowledge, hospitality service skill, and work attitude. Rao, Monin, and Durand (2003) indicated that French-style cuisine emphasized imagination, cross culture, and the individual creativity of cooks in the course of evolution. Ruhlman (2001) argued that cooking must be customer-oriented and make people happy via its underlying characteristics, excellent cooking skills, knowledge, sense of humor, creativity, and wisdom.

Hygiene/safety. Food hygiene and safety are paramount concerns related to consumers' trust in culinary products, and the characteristic of trust involves obtaining further information on the products. Röhr, Lüddecke, Drusch, Muller, and Alvensleben (2005) researched the confirmation of food hygiene and safety through intensified inspection, in which the consumers are willing to pay a higher price to purchase the inspected food, in order to completely ensure the food safety. Unusan (2007) reported that actual self-reported behaviors of food-handling support a higher level of food safety competency than that indicated by self-reported food-safety-management competence, which scored low across all age groups. Food safety is an increasingly important factor influencing consumer trust in overall food quality (Aggelogiannopoulos, Drosinos, \& Athanasopoulos, 2007) and is of central importance to consumers, the food industry, and the economy (Jevsnik 
et al., 2008). Effective and relevant food safety training provided by food-related organizations, adequate resources, and colleague support are all important factors for improving food handling and workplace safety practices (Ko, 2010). Safe food handling practices depend on the ability to link together the three food-handler aspects: positive behavior, attitudes, and continued education (Howes, McEwen, Griffiths, \& Harris, 1996).

Environment/ambiance. Seo and Shanklin (2006) pointed out that in addition to the characteristics of food, many environmental factors influence the customers' recognition of the hospitality quality, such as the variety of food choice (Bell, Meiselman, Pierson, \& Revee, 1994), restaurant decoration and presentation of background music (Meiselman, Hedderley, Staddon, Pierson, \& Symonds, 1994), as well as the dining etiquette conforming to the restaurant environment (P. Jones \& P. A. Jones, 1990).

Marketing/promotion. P. Jones and P. A. Jones (1990) pointed out that the complex experience in dining out may result in stress for many customers, and suggested reducing this stress in hospitality by the following means: establishing clear rules (e.g., the procedures and rules for dish ordering), providing information (e.g., the time from dish ordering to delivering), dining environment (e.g., enough private space), and providing personnel training, in order to improve customer satisfaction. External conditions such as price, brand, packaging, and purchase place may also influence the customers' views on food quality (Schröder, 2003). Moreover, Dodds, Monroe, and Grewal (1991) indicated that when price is the only available clue, the interviewee would clearly consider that price is positively correlated with quality. Shiv, Carmon, and Ariely (2005) argued that price could play an unconscious role in influencing the expectations of consumers to products as well as the actual product performance.

Service. The importance of personnel in the service industry is obvious. Sasser, Olsen, and Wyckoff (1978) suggested that service level is akin to "quality"; "service level” means the degree of tangible and intangible benefits provided by the service providers to the customers and can be classified into expected service level and perceived service level.

This study considers foodservice quality in terms of six dimensions from the perspectives of food-related and consumer preference-related concerns.

\section{Factors Influencing the Perception Competences of Students With Regard to Foodservice Quality}

Foodservice competence. Competence is a term often used to define professional and undergraduate curriculum requirements. Competencies often include "soft" skills such as respecting diversity, developing trusting relationships, adapting to change, and working in a team that comprises content area expertise (Mackey \& Thomas, 2002). Competencies should be integrated into the development of theoretical knowledge and performance capabilities in class projects, activities, team assignments, internships, service learning, and general education courses (Giberson, 2010). Professional competence is defined as the ability of employees to apply professional knowledge, skills, motives, and traits to work conditions (Litchfield, Oakland, \& Anderson, 2002).

Ko and Hsiao (2008) found that foodservice knowledge is the most important factor influencing foodservice quality, followed by personal characteristics and communication. Kriegl (2000) found food safety to be the most important foodservice industry management skill. The rapid growth in the hospitality sector and foodservice industry in Taiwan has increased operators' awareness of the critical significance of F\&B quality. Taiwan's higher education institutions have thus opened and expanded related academic programs in hospitality and foodservice management and marketing and tourism and restaurant marketing. Professional foodservice and culinary education is an important and growing segment of higher education in Taiwan, and most hospitality students have industry internship experiences prior to graduation (Horng, 2004). 
The relationship between hospitality courses and foodservice competence. Hospitality education prepares students for future management positions through relevant business and social science courses. Curriculum planners coordinate closely with industry on coursework design formulation and arrange practical internships to enhance educational efficacy (Barrows \& Bosselman, 1999). Christou (1999) found that hospitality education in Taiwan provides a critical foundation for managerial skill growth and development in the hospitality sector.

University-level hospitality education teaches theory and practical skills and provides students with the opportunities to participate in practical training or internships. Increasing competition in the workplace requires that the mission, strategic objectives, purposes, and educational processes of hospitality education be reevaluated/adjusted regularly in order to match market expectations (Barrows \& Bosselman, 1999). Vocational college and university coursework today introduces and discusses relevant theories, applies theory to practice, highlights case studies, discusses current job market realities, prepares students for myriad workplace challenges, integrates cognitive, emotive, and technical proficiencies, and helps foster practical problem-solving skills. Hospitality management courses typically work to provide a full-spectrum education that covers both practical skills and management theory. In general, hospitality management courses may be ordered into several categories that include: hospitality skills, management (professional and general management), information technology, communications and expressive communications, career planning and development, practical internships, and research methodology (Horng, 2007).

Most culinary courses focus primarily on elucidating practical work requirements (Zerdin, 1994), at each level of management to establish educational objectives and relevant coursework design. Courses designed for vocational-technical students at the high school or post-high school levels focus primarily on teaching basic skills, with specialized training focusing on developing mid-tier managers, and college and university hospitality courses focusing on developing senior hospitality and hotel managers (Barrows \& Bosselman, 1999). As many hospitality students find employment in the F\&B sector following graduation, hospitality education programs tailor their curricula to professional career demands by teaching practical skills, food-ingredient principles, management, communications, and providing internship opportunities (Teng, 2008).

The main factor that influences the students' perception of hospitality quality is school courses (Horng, 2007). This study referred to the hospitality courses of universities and colleges and classified the courses into cuisine art course (e.g., Chinese cuisine, western cuisine, and baking), management course (e.g., restaurant operation management, purchasing and culinary culture), and other courses (e.g., hotel and restaurant English), including internship. "Hospitality education" comprises a series of courses designed for the students in preparation for a career in management, and the students benefit from the educational models that combine business and social science. Therefore, in the design of courses, there is a close link with industry, while internship is one of the important approaches to acquire the actual work experience (Barrows \& Bosselman, 1999). The work-based learning in hospitality education (Raelin, 1997) is a common learning method. With the emphasis on the value of work experience, apprenticeship is a means to develop management skills and reflect the social development status. The purpose of this teaching model is to make students participate in the discussions on some phenomena, reflect on their thoughts and actions during the process, and practice the skills taught in class, in order to accelerate their development of knowledge and technology (Margerison, 1988). 


\section{Methodology}

\section{The Sample and Data Collection}

One hundred questionnaires were distributed for pre-testing in March 2012 by two university students (seniors of the hospitality department) in Taipei, of which 98 were returned valid. The final questionnaire was designed based on item analysis and factor analysis of results during the pre-testing period. The original questionnaires were with 62 items, and we delete five items with lower factor loading for final questionnaires.

Formal questionnaire was based on purposive sampling. All of the participants had attended all theoretical and practical culinary classes (culinary courses including Chinese cuisine, western cuisine, baking and beverage; hospitality professional courses including food principle, culinary culture, restaurant operation management, purchasing, menu design, restaurant payout, food service, and food hygiene and safety; and general management courses including marketing, consumer behavior, hotel and restaurant English, and information technology) and they had finished internships of more than 240 hours in the foodservice industry. The subjects were third-year and senior students from the hospitality departments of two universities respectively in north, central, and south Taiwan. After contacting with teachers, we mailed the questionnaires to universities. Once teachers of the department finished the class, they invited the students who agreed to accept the test to fill in the questionnaires and send them back. A total of 150 samples were distributed in northern Taiwan, and 141 were retrieved, with a return rate of 94\%; 100 were distributed in central Taiwan, and 88 were retrieved, with a return rate of 88\%; 150 were distributed in southern Taiwan, and 126 were retrieved, with a return rate of $84 \%$. A total of 400 questionnaires were distributed, and 355 valid samples were retrieved, with a valid return rate of $88.75 \%$.

\section{Measurements}

The questionnaire collected data from respondents in three categories: (1) self-perceived importance and competence in the six foodservice quality dimensions of product characteristics, culinary skill, food safety, environment and ambiance, sales and promotion, and service quality; (2) courses contribution effectiveness for foodservice quality ability; and (3) socio-demographic information.

The construction of foodservice quality items referred to the findings of Ko and Su (2013) as well as study research team discussions. The foodservice quality questionnaire included 57 items across the six constructs of product characteristics (nine items), culinary skill (five items), food safety (12 items), environment and ambiance (13 items), sales and promotion (five items), and service quality (13 items). Good reliability for the six constructs was demonstrated by a Cronbach's $\alpha$ range for perceived importance of 0.858-0.934 and a perceived competence range of 0.908-0.947 for main survey.

The scale used a 5-point Likert scale ranging from 1 (unimportant/incapability) to 5 (highly important/high level of capability) to measure the perceived importance of and competence in foodservice quality on the part of the participants. Regarding the contribution (\%) of hospitality courses to foodservice quality competence, the students evaluated whether the course provided the foodservice quality ability, where 1 signifies providing this ability (Yes) and 0 signifies not providing this ability (No).

\section{Data Analysis}

The collected data were analyzed using Statistical Package for Social Sciences (SPSS), Version 18.0. Descriptive statistics and regression analysis analyzed the differences among the variables. Importance-performance analysis (IPA) identified participant perceptions regarding the relationships between 
importance and performance. The foodservice quality factors' means for the perceived importance and the performance of each factor were calculated and plotted onto a graph. Mean values for the importance-performance intersect coordinates of participant foodservice quality perceptions were calculated to separate the factors into four identifiable quadrants. The data were then presented on a grid, with each factor plotted based on its perceived importance and performance. This two-dimensional grid measures the importance of foodservice quality on its vertical axis from high (top) to low (bottom), and the performance of foodservice quality on its horizontal axis from high (right) to low (left). The graphical representation of the data produced four quadrants.

\section{Result and Discussion}

In terms of socio-demographics, 235 participants (66.2\%) were female and 120 (33.8\%) were male; all were either third-year students $(123,34.6 \%)$ or seniors $(232,65.4 \%)$. In terms of hospitality internship experience, most had 1-2 years of internship experience, with the second largest number having completed less than one year.

\section{Participants’ Perceived Importance of and Competence in Foodservice Quality}

Analysis of participants' self-evaluated food quality importance perceptions and foodservice quality self-competence performance indicated importance at mean values of 4 or higher, and with close values. Of the six dimensions, "food safety" scored the highest and "product characteristics" scored the lowest (see Table 1). In terms of participant competence, mean scores were higher than the mid-point of 3. "Service quality" scored the highest and "culinary skill” scored the lowest (see Table 2).

Table 1

Mean and S.D. Values for Dimensions of Perceived Foodservice Quality Importance

\begin{tabular}{llll}
\hline Dimension & Mean $^{\mathrm{a}}$ & S.D. & Ranking \\
\hline Product characteristics & 4.35 & 0.491 & 6 \\
Culinary skill & 4.46 & 0.539 & 3 \\
Food safety & 4.52 & 0.477 & 1 \\
Environment and ambiance & 4.45 & 0.478 & 4 \\
Sales and promotion & 4.43 & 0.535 & 5 \\
Service quality & 4.50 & 0.448 & 2 \\
Total & 4.46 & 0.409 & \\
\hline
\end{tabular}

Note. ${ }^{\text {a }}$ : The study uses a 5-point Likert scale ranging from 1 to 5.

Table 2

Mean and S.D. Values for Dimensions of Perceived Foodservice Quality Competence

\begin{tabular}{llll}
\hline Dimension & Mean $^{\mathrm{a}}$ & S.D. & Ranking \\
\hline Product characteristics & 4.01 & 0.582 & 5 \\
Culinary skill & 3.83 & 0.727 & 6 \\
Food safety & 4.08 & 0.614 & 4 \\
Environment and ambiance & 4.14 & 0.590 & 2 \\
Sales and promotion & 4.13 & 0.640 & 3 \\
Service quality & 4.22 & 0.553 & 1 \\
Total & 4.10 & 0.519 & \\
\hline
\end{tabular}

Note. ${ }^{\text {a }}$ : The study uses a 5-point Likert scale ranging from 1 to 5. 


\section{Foodservice Quality: The Gap Between Perceived Importance and Perceived Competence Among Participants}

This study used a paired sample $t$-test to test the importance of foodservice quality and the differences in levels of performance (competence) among the various dimensions. In addition, this study used IPA to distribute various dimensions of hospitality quality into four quadrants, with each quadrant analyzed separately. The results found significant differences in importance and level of fulfillment among the dimensions and the total dimension of hospitality quality (see Table 3). Furthermore, perceived importance was greater than the perceived level of competence for foodservice quality in all the dimensions. This finding suggests that participants perceive all foodservice quality dimensions as important and that the levels of perceived competence should be strengthened.

Table 3

Results of Paired Sample T-test on Perceived Importance and Competence in Foodservice Quality Dimensions

\begin{tabular}{|c|c|c|c|c|c|c|}
\hline Dimension & $\begin{array}{l}\text { Perception } \\
\text { variable }\end{array}$ & Number & Mean & S.D. & $t$-value & $p$-value \\
\hline \multirow{2}{*}{ Product characteristics } & Importance & 355 & 4.347 & 0.491 & \multirow[t]{2}{*}{10.001} & \multirow[t]{2}{*}{$0.000^{* * * *}$} \\
\hline & Competence & 355 & 4.005 & 0.582 & & \\
\hline \multirow{2}{*}{ Culinary skill } & Importance & 355 & 4.463 & 0.539 & \multirow[t]{2}{*}{14.174} & \multirow[t]{2}{*}{$0.000^{* * *}$} \\
\hline & Competence & 355 & 3.825 & 0.727 & & \\
\hline \multirow{2}{*}{ Food safety } & Importance & 355 & 4.522 & 0.477 & \multirow[t]{2}{*}{12.915} & \multirow[t]{2}{*}{$0.000^{* * *}$} \\
\hline & Competence & 355 & 4.080 & 0.614 & & \\
\hline \multirow{2}{*}{ Environment and ambiance } & Importance & 355 & 4.447 & 0.478 & \multirow[t]{2}{*}{9.397} & \multirow[t]{2}{*}{$0.000^{* * *}$} \\
\hline & Competence & 355 & 4.141 & 0.590 & & \\
\hline \multirow{2}{*}{ Sales and promotion } & Importance & 355 & 4.426 & 0.535 & \multirow[t]{2}{*}{8.136} & \multirow[t]{2}{*}{$0.000^{* * *}$} \\
\hline & Competence & 355 & 4.132 & 0.640 & & \\
\hline \multirow{2}{*}{ Service quality } & Importance & 355 & 4.499 & 0.448 & \multirow[t]{2}{*}{9.073} & \multirow[t]{2}{*}{$0.000^{* * *}$} \\
\hline & Competence & 355 & 4.220 & 0.553 & & \\
\hline \multirow{2}{*}{ Total dimensions } & Importance & 355 & 4.459 & 0.409 & \multirow[t]{2}{*}{12.495} & \multirow[t]{2}{*}{$0.000^{* * *}$} \\
\hline & Competence & 355 & 4.096 & 0.519 & & \\
\hline
\end{tabular}

Note. $^{* * * *}: p<0.001$.

This study used IPA to distribute all the dimensions of foodservice quality into four quadrants and performed analyses separately in each. Figure 1 shows significant differences in perceived importance and perceived competence between each of the six dimensions and the total dimensions of food quality. Moreover, perceived importance was greater than perceived competence for all dimensions. This indicates that participants perceive all foodservice quality dimensions as important and that perceived competence should be strengthened. This study used IPA to analyze importance as the $\mathrm{X}$ axis and level of fulfillment as the $\mathrm{Y}$ axis. The point at which the mean $(M=4.46)$ of the total dimensions of importance and the mean $(M=4.10)$ of the total dimensions of level of fulfillment intersected was the center. All dimensions were divided into four quadrants for further investigation. "Service quality" was located at "keep up the good work". Regarding foodservice quality, as students suggested that service quality is important, the capacity should be maintained. "Environment and ambiance" and "sales and promotion" are located at "possible overkill”; thus, students have a sufficient cognition of the two dimensions. "Product characteristics" and "culinary skill” are located at "low priority" (low importance and low level of performance); thus, product characteristics and culinary skill are less important and performance is low. The reason is that students are basic employees and they have low performance of products. 
The result may be different from high-rank employees. Finally, "food safety" is located at "concentrate here”. It shows that most students realize that food safety is important. However, their self-perceived competence is low. Course design and educational training can reinforce the knowledge and capacity. The results thus suggest that schools prioritize the improvement of foodservice safety-related courses.

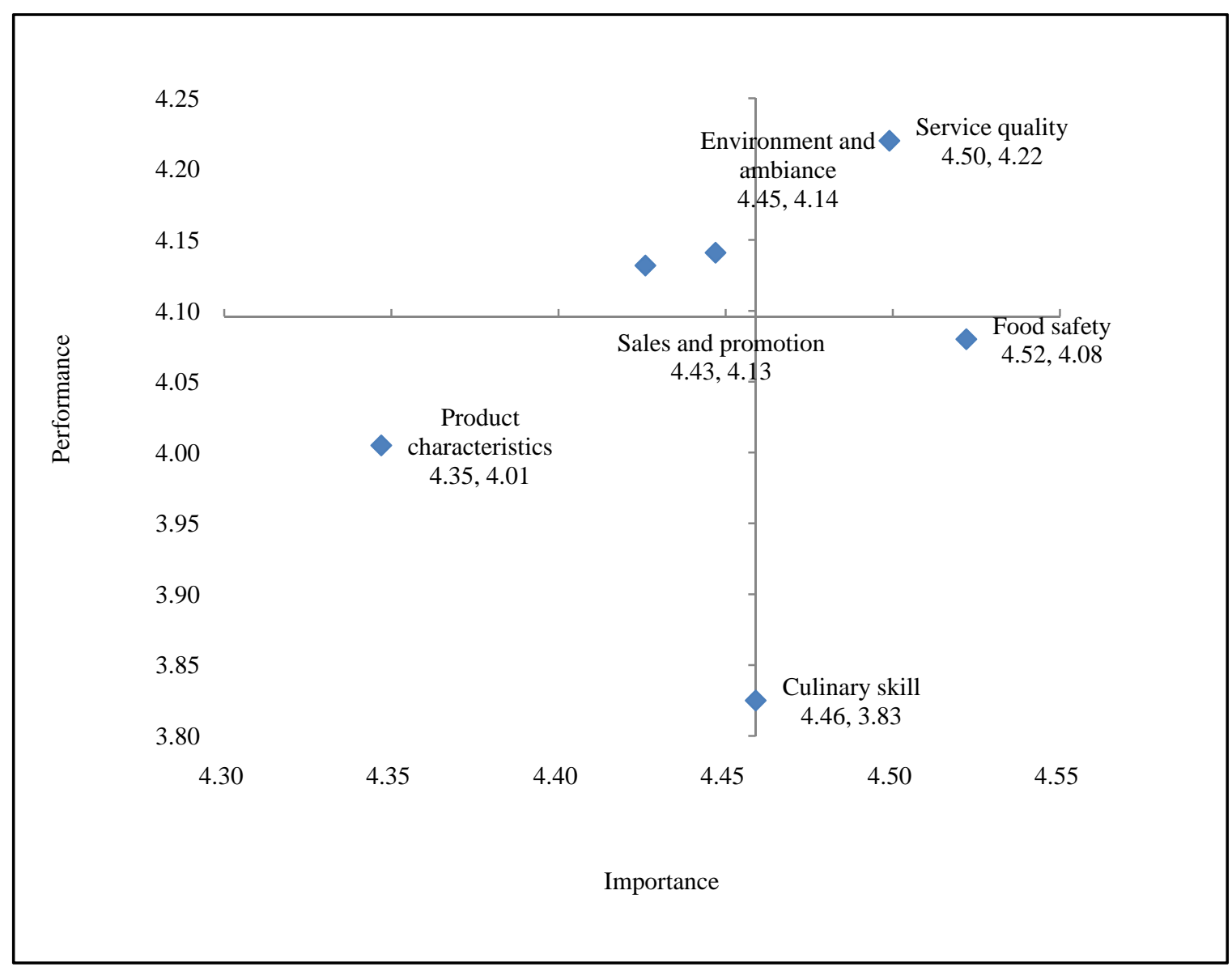

Figure 1. IPA of perceived importance of and competence in foodservice quality.

\section{The Contribution of Hospitality Courses to the Competence of Foodservice Quality}

From the literature, hospitality education provides lecture and practice courses in school and internship courses in industry. Table 4 presents the courses and internship experience predicted $26.4 \%$ of the variability in perceived competence of foodservice quality. Both the two variables showed a statistical significance $(p<0.05)$.

Table 4

Effects of Course and Internship Experience on the Perceived Competence of Foodservice Quality for Hospitality Students

\begin{tabular}{llllll}
\hline Variable & Beta coefficient & Standard error & $\begin{array}{l}\text { Standardized beta } \\
\text { coefficient }\end{array}$ & $t$-value & Significance \\
\hline Course & 0.431 & 0.059 & 0.475 & 7.255 & 0.000 \\
Internship experience & 0.130 & 0.048 & 0.178 & 2.716 & 0.003 \\
\hline
\end{tabular}

Notes. Multiple $R=0.514 ; R^{2}=0.264 ; F=30.914$; Significance $F=0.0000$. 
The findings indicated that course match and internship experience had a significant effect on the competence of foodservice quality. In order to elicit the type of courses that enhance foodservice quality perceptions, hospitality courses were further divided into three course categories: culinary, hospitality professional, and general management. Participants' perceptions regarding the contribution of each to foodservice quality were then assessed.

After completing culinary courses, the perceived competence of food quality participants focused on “culinary skill”, “food safety”, and "product characteristics”; hospitality professional course provided more competence of "product characteristics"; and the general management courses provided the competences on "sales and promotion" and "service quality" (see Table 5). Hospitality professional courses provide not only management knowledge but also knowledge applicable to marketing management and service training courses. Based on previous findings, as to school course design, culinary skill course can be strengthened. In addition, if students have the opportunity to work in the kitchen, they would enhance "culinary skill” in practice, "food safety”, and "product characteristics”, and further increase foodservice quality.

Table 5

The Contribution (\%) ${ }^{*}$ of Hospitality Courses to Foodservice Quality Ability

\begin{tabular}{|c|c|c|c|c|c|c|c|}
\hline Course & Foodservice quality dimension & $\begin{array}{l}\text { Product } \\
\text { characteristic }\end{array}$ & $\begin{array}{l}\text { Culinary } \\
\text { skill }\end{array}$ & $\begin{array}{l}\text { Food } \\
\text { safety }\end{array}$ & $\begin{array}{l}\text { Environment } \\
\text { and ambiance }\end{array}$ & $\begin{array}{l}\text { Sales and } \\
\text { promotion }\end{array}$ & $\begin{array}{l}\text { Service } \\
\text { quality }\end{array}$ \\
\hline \multirow{4}{*}{ Culinary courses } & Chinese cuisine and practice & 87.6 & 97.7 & 92.4 & 14.1 & 5.4 & 14.4 \\
\hline & Western cuisine and practice & 90.7 & 97.2 & 91.0 & 21.4 & 7.0 & 14.4 \\
\hline & Baking & 87.9 & 95.7 & 90.1 & 14.6 & 12.1 & 12.1 \\
\hline & Beverage & 87.7 & 79.1 & 83.9 & 24.3 & 18.5 & 21.2 \\
\hline \multirow{8}{*}{$\begin{array}{l}\text { Hospitality } \\
\text { professional } \\
\text { courses }\end{array}$} & Food principles & 96.5 & 31.3 & 78.1 & 19.9 & 24.0 & 24.0 \\
\hline & Culinary culture & 90.8 & 21.4 & 49.2 & 48.5 & 39.3 & 35.9 \\
\hline & Restaurant operations management & 63.7 & 24.4 & 55.5 & 70.6 & 93.6 & 83.7 \\
\hline & Restaurant purchasing & 85.1 & 11.8 & 67.9 & 19.0 & 54.1 & 25.2 \\
\hline & Menu design & 82.6 & 20.6 & 26.5 & 31.8 & 89.4 & 38.8 \\
\hline & Restaurant layout and planning & 48.1 & 10.6 & 57.1 & 96.5 & 57.1 & 48.4 \\
\hline & Food service & 60.6 & 14.4 & 42.3 & 65.1 & 59.2 & 97.5 \\
\hline & Food hygiene and safety & 62.2 & 12.0 & 98.3 & 27.5 & 16.6 & 24.4 \\
\hline \multirow{4}{*}{$\begin{array}{l}\text { General } \\
\text { management } \\
\text { courses }\end{array}$} & Marketing & 39.5 & 1.2 & 2.9 & 21.6 & 98.5 & 50.6 \\
\hline & Consumer behavior & 39.2 & 0.9 & 4.7 & 24.7 & 94.0 & 77.5 \\
\hline & Hotel and restaurant English & 50.4 & 2.0 & 0.8 & 34.9 & 56.1 & 87.3 \\
\hline & $\begin{array}{l}\text { Hotel and restaurant information } \\
\text { technology systems }\end{array}$ & 55.4 & 1.2 & 1.5 & 17.1 & 87.2 & 60.6 \\
\hline
\end{tabular}

Note. : : The students evaluated whether the course provided the foodservice quality ability, where 1 signifies providing this ability (Yes) and 0 signifies not providing this ability (No). The contributions (\%) of hospitality courses were counted to the total of students evaluated the each course provided the ability of foodservice.

\section{Conclusions}

The results of this study indicate that students perceive "food safety" and "food characteristics" as of the highest and the lowest importance, respectively. In terms of the six self-perceived competency dimensions, "service quality" earned the highest and "culinary skill” earned the lowest scores. Satisfaction with hospitality courses was significantly associated with the competencies of foodservice quality. In terms of the influence of hospitality courses, the results of this study indicate that culinary courses most improve participants' knowledge and skills in the dimensions of "culinary skill”, "food safety", and "product characteristics"; 
hospitality professional courses most improve knowledge and skills in the dimensions of "product characteristics", "food safety", and "sales and promotion"; and general management courses most improve knowledge and skills in the dimensions of "sales and promotion", "service quality", and "product characteristics". Culinary courses had a greater impact on the perceptions of foodservice quality than either hospitality professional or general management courses. The hospitality courses were useful to increase the perception competence of the foodservice quality for hospitality students. Furthermore, study data found associations between each of the three course categories and all six foodservice quality perspective dimensions.

\section{Discussion and Suggestion}

This study found that participants perceived "product characteristics" as the least important in terms of food quality. In light of this, we recommend enhancing teaching in the areas of culinary principles, restaurant purchases, culinary culture, and hygiene and safety in order to enhance students' appreciation of the special characteristics of food and food quality. Study of participants showed that they appreciated the impact of the service quality dimension on food quality and were well prepared in this area. Hospitality programs may build on these strengths while planning new courses in order to maintain food service and environmental planning/design-related classes for enhancing students' appreciation of and abilities in hospitality service.

Although current post-secondary school curricula effectively enhance students' food quality perception capabilities, this study found that hospitality students still had significant room for improvement. Therefore, we recommend that curriculum requirements expand innovative course offerings to give students greater hands-on operational experience and enhance technical, hygiene, and safety management proficiencies. Because of the apparent benefit of curriculum expansions to hospitality students, hospitality programs should build from the strengths highlighted in this study and plan new courses to extend F\&B-related and environmental planning/design courses, as well as help students gain significantly more hospitality service-related experience and knowledge. Curricula should be designed to further enhance the focus of students on critical issues of importance to their field and on professional readiness. In terms of the several dimensions considered in this paper, food management courses and food preparation principles may help students better appreciate the significance of food quality. In terms of preparedness, each of the kitchen-related courses as well as practical experience may enhance students' food quality readiness/preparedness. It is recommended that students engage in off-campus internships or employment in addition to on-campus courses, to further enhance their food quality preparedness. Hospitality education prepares students for future management positions using curricula that teach hospitality-related technical skills and provides a diverse grounding in business and the social sciences. Horng (2007) stated that advanced hospitality courses in food and nutrition, food preparation, F\&B, food selection and storage, food safety and hygiene, and foodservice enhance the practical skills of hospitality students.

Courses are often designed in close coordination with industry, and practical experience internships are a critical part of the hospitality education experience (Barrows \& Bosselman, 1999). Technology education requires the development of professional competencies in order for students to obtain higher university scores or participate effectively in competitions (L. G. Boussiakou, Kalkani, \& I. K. Boussiakou, 2009). University education provides basic professional technical knowledge and professional job skills. Similarly, professional internships and institutions instill capabilities and competencies needed in a professional capacity and help bridge the gap between academic and employer needs (Giberson, 2010). However, this study found that the 
professional knowledge of the students with regard to hospitality quality derived from school courses, suggesting that the course design will influence the students' future perception towards hospitality. This should be noted in university education. The research results shown in Table 5 can provide an important basis for scholars of hospitality education in relation to course design and the segmentation of course contents.

In addition, this study result may provide reference for educators to improve relevant courses. Course content, for example, may be amended to enhance students' understanding of hospitality products and increase the importance attached by students to hospitality quality. The hospitality-related departments may increase cooking skill-related courses to enable students to improve their food preparation and health and safety management skills through practical applications. Internships in the hospitality industry or work study programs generally assign hospitality students to work as first-line service personnel. This also suggests that their service quality may be better than indicated in the self-assessment questionnaire. Foodservice operators may consider increasing opportunities for interns to participate in management level activities to help them better understand the hospitality industry and increase their willingness to join the hospitality industry after graduation.

Several limitations prevent the generalization of the study results beyond the region in Taiwan in which data were collected. Furthermore, questionnaire responses were self-reported; thus, this study assumed that all participants answered honestly. Future studies may identify additional factors, such as internship experience and work time that may affect the foodservice quality perceptions of students. A cross-sectional comparison of hospitality students may also be undertaken to identify the consistency of results across groups and geographic regions.

\section{References}

Acebron, L. B., \& Dopico, D. C. (2000). The importance of intrinsic and extrinsic cues to expected and experienced quality: An empirical application for beef. Food Quality and Preference, 11(3), 229-238.

Aggelogiannopoulos, D., Drosinos, E. H., \& Athanasopoulos, P. (2007). Implementation of a quality management system (QMS) according to the ISO 9000 family in a Greek small-sized winery: A case study. Food Control, 18(9), 1077-1085.

Baldwin, C. Y., \& Clark, K. B. (1997). Managing in an age of modularity. Harvard Business Review, 75(5), 84-93.

Barrows, C. W., \& Bosselman, R. H. (1999). Hospitality management education. Binghamton, NY: The Haworth Hospitality Press.

Bell, R., Meiselman, H. I., Pierson, B. J., \& Reeve, W. G. (1994). Effects of adding an Italian theme to a restaurant on the perceived ethnicity, acceptability, and selection of foods. Appetite, 22(1), 11-24.

Boussiakou, L. G., Kalkani, E. C., \& Boussiakou, I. K. (2009). Quality assurance for higher and technological education in Greece. World Transactions on Engineering and Technology Education, 7(1), 82-87.

Christou, E. S. (1999). Hospitality management education in Greece: An exploratory study. Tourism Management, 20(6), 683-691.

Dodds, W. B., Monroe, K. B., \& Grewal, D. (1991). Effects of price, brand, and store information on buyers' product evaluations. Journal of Marketing Research, 28(3), 307-319.

Giberson, T. R. (2010). Performance capabilities and competencies at the undergraduate and graduate levels for performance improvement professional. Performance Improvement Quarterly, 22(4), 99-120.

Horng, J. S. (2004). Curriculum analysis of foods and beverage management of technological and vocational education in Taiwan. Asia Pacific Journal of Tourism Research, 9(2), 107-119.

Horng, J. S. (2007). The course development and planning for hospitality program. Taipei: National Normal University Bookstore.

Howes, M., McEwen, S., Griffiths, M., \& Harris, L. (1996). Food handler certification by home study: Measuring changes in knowledge and behavior. Dairy, Food, and Environmental Sanitation, 16, 737-744. 
Jevsnik, M., Hlebec, V., \& Raspor, P. (2008). Consumers' awareness of food safety from shopping to eating. Food Control, 19(8), 737-745.

Johns, N., Tyas, P., Ingold, T., \& Hopkinson, S. (1996). Investigation of the perceived components of the meal experience, using perceptual gap methodology. Progress in Tourism and Hospitality Research, 2(1), 15-26.

Jones, P., \& Jones, P. A. (1990). Stress: Are you serving it up to your restaurant patrons? The Cornell Hotel and Restaurant Administration Quarterly, 31(3), 38-43.

Kivela, J., Inbakaran, R., \& Reece, J. (1999). Consumer research in the restaurant environment. Part 1: A conceptual model of dining satisfaction and return patronage. International Journal of Contemporary Hospitality Management, 11(5), 205-222.

Kivela, J., Inbakaran, R., \& Reece, J. (2000). Consumer research in the restaurant environment. Part 3: Analysis, findings, and conclusions. International Journal of Contemporary Hospitality Management, 12(1), 13-30.

Ko, W. H. (2010). Evaluating food safety perceptions and practices for agricultural food handler. Food Control, 21(4), $450-455$.

Ko, W. H., \& Hsiao, C. Y. (2008). To evaluate the professional competency of chef-applying in analysis hierarchy process. Journal of Hospitality and Home Economics, 5(1), 69-91.

Ko, W. H., \& Su, L. J. (2013). Food quality: Importance perceptions and self-efficacy among hospitality students in Taiwan. Proceedings of the 1st World Conference on Hospitality, Tourism, and Event Research and International Convention and Expo Summit, Bangkok, Thailand, May 25-28.

Kriegl, U. (2000). International hospitality management: Identifying important skills and effective training. The Cornell Hotel and Restaurant Administration Quarterly, 41(2), 64-71.

Lin, L. (2007). The development of a scale for evaluating creative culinary products (Master dissertation, National Taiwan Nornmal University). Retrieved from http://ndltd.ncl.edu.tw/cgi-bin/gs32/gsweb.cgi/ccd=bNwFO7/record?r1=5\&h1=1

Litchfield, R. E., Oakland, M. J., \& Anderson, J. (2002). Promoting and evaluating competence in on-line dietetics education. Journal of the American Dietetic Association, 102(10), 1455-1458.

Mackey, D. L., \& Thomas, C. (2002). Human resource managers' perceptions of competencies to be included in an undergraduate program. Proceedings of the 2002 Academy of HRD Conference. Academy of Human Resource Development.

Margerison, C. (1988). Action learning and excellence in management development. Journal of Management Development, 7(5), 43-53.

Meiselman, H. L. (2008). Dimensions of the meal. Journal of Foodservice, 19(1), 13-21.

Meiselman, H. L., Hedderley, D., Staddon, S. L., Pierson, B. J., \& Symonds, C. R. (1994). Effect of effort on meal selection and meal acceptability in a student cafeteria. Appetite, 23(1), 43-55.

Namkung, Y., \& Jang, S. (2007). Does food quality really matter in restaurants? Its impact on customer satisfaction and behavioral intentions. Journal of Hospitality and Tourism Research, 31(3), 387-409.

Olsen, J. R., Harmsen, H., \& Friis, A. (2008). Linking quality goals and product development competences. Food Quality and Preference, 19(1), 33-42.

Parsa, H. G., Self, J. T., Njite, D., \& King, T. (2005). Why restaurants fail? The Cornell Hotel and Restaurant Administration Quarterly, 46(3), 304-322.

Peneau, S., Hoehn, E., Roth, H. R., Escher, F., \& Nuessli, J. (2006). Importance and consumer perception of freshness of apples. Food Quality and Preference, 17(1-2), 9-19.

Peri, C., Lavelli, V., \& Marjani, A. (2004). Qualità nelle aziende e nelle filiere agroalimentari. Milano: Hoepli.

Raelin, J. A. (1997). A model of work-based learning. Organization Science, 8(6), 563-578.

Rao, H., Monin, P., \& Durand, R. (2003). Institutional change in Toque Ville: Nouvelle cuisine as an identity movement in French gastronomy. The American Journal of Sociology, 108(4), 795-843.

Röhr, A., Lüddecke, A., Drusch, S., Muller, M. J., \& Alvensleben, R. V. (2005). Food quality and safety: Consumer perception and public health concern. Food Control, 16(8), 649-655.

Ruhlman, M. (2001). The soul of a chef: The journey toward perfection. New York, NY: Penguin.

Sanderson, S., \& Uzumeri, M. (1995). Managing product families: The case of the Sony Walkman. Research Policy, 24(5), 761-782.

Sasser, W. E., Olsen, R. P., \& Wyckoff, D. D. (1978). Management of service operations: Text, cases, and readings. Boston: Alley \& Bacon.

Schröder, M. J. A. (2003). Food quality and the consumer value: Delivering food that satisfies. New York, NY: Springer-Verlag. 
Seo, S., \& Shanklin, C. W. (2006). Using focus groups to determine specific attributes that influence the evaluation of quality food and service quality in continuing care retirement communities. Journal of Foodservice Business Research, 8(1), 35-51.

Shiv, B., Carmon, Z., \& Ariely, D. (2005). Placebo effects of marketing actions: Consumers may get what they pay for. Journal of Marketing Research, 42(4), 383-393.

Sulek, J. M., \& Hensley, R. L. (2004). The relative importance of food, atmosphere, and fairness of wait: The case of a full-service restaurant. The Cornell Hotel and Restaurant Administration Quarterly, 45(3), 235-247.

Teng, C. C. (2008). The effects of personality traits and attitudes on student uptake in hospitality employment. International Journal of Hospitality Management, 27(1), 76-86.

Unusan, N. (2007). Consumer food safety knowledge and practices in the home in Turkey. Food Control, 18(1), 45-51.

Wright, O. R. L., Connelly, L. B., \& Capra, S. (2006). Consumer evaluation of hospital foodservice quality: An empirical investigation. International Journal of Health Care Quality Assurance, 19(2-3), 181-194.

Yang, W. W. (2003). A study on professional competencies of chefs: Comparisons of food and beverage teachers' and chefs' conceptions on chefs' professional competencies. National Yunlin University of Science Technology. Retrieved from http://ndltd.ncl.edu.tw/cgi-bin/gs32/gsweb.cgi/ccd=bNwFO7/record?r1=6\&h1=2

Zerdin, D. (1994). Application of a curriculum model. Paper presented at the Tutors and Examiners Conference, Communication, Advertising, and Marketing Foundation, London. 